\title{
Malaysian child infected with Plasmodium vivax via blood transfusion: a case report
}

\author{
Claudia N Anthony ${ }^{1 \dagger}$, Yee-Ling Lau ${ }^{1 *}{ }^{*}$, Jia-Siang Sum ${ }^{1}$, Mun-Yik Fong ${ }^{1}$, Hany Ariffin², Wai-Linn Zaw ${ }^{3}$, \\ Indra Jeyajothi ${ }^{2}$ and Rohela Mahmud ${ }^{1}$
}

\begin{abstract}
Malaria may be a serious complication of blood transfusion due to the asymptomatic persistence of parasites in some donors. This case report highlights the transfusion-transmitted malaria of Plasmodium vivax in a child diagnosed with germ cell tumour. This child had received blood transfusion from three donors and a week later started developing malaria like symptoms. Nested PCR and sequencing confirmed that one of the three donors was infected with P. vivax and this was transmitted to the 12-year-old child. To the best of the authors' knowledge, this is the first reported transfusion-transmitted malaria case in Malaysia.
\end{abstract}

Keywords: Plasmodium vivax, Blood transfusion, Malaria transmission, Endemic regions, Microscopy, PCR

\section{Background}

Although transfusion therapy aids in saving lives, blood can serve as a means to transmit infections, including parasitic infections [1]. Although the incidence of blood transfusion-transmitted parasitic infections (TTPI) is admittedly lower compared to viral and bacterial infections, it is important to understand that parasites can cause ailment, especially in immunocompromised individuals [2] Transfusion-transmitted malaria (TTM) occurs when the patient is infected by the same parasite that was present in the donor's blood. TTM was first reported in 1911 [2-4]. While parasitic infections transmitted via accidental exposure to infected blood or blood transfusion may occasionally be difficult to diagnose in regions/areas where these infections are not endemic, such is usually not the case. TTM is in fact much harder to be identified in endemic countries as majority of donors may be potentially infected with malaria parasites [3]. Precise data on the incidence of TTM are under-reported in malaria-endemic areas, where recipients are known to have pre-existing infection. In non-endemic regions, the reported incidences range from zero to two cases per million donations [5]. As far as the authors are concerned, this is the

\footnotetext{
* Correspondence: lauyeeling@um.edu.my

${ }^{\dagger}$ Equal contributors

'Department of Parasitology, Faculty of Medicine, University Malaya, 50603,

Kuala Lumpur, Malaysia

Full list of author information is available at the end of the article
}

first transfusion-acquired Plasmodium vivax malaria case reported in Malaysia.

\section{Case presentation}

A 12-year-old Chinese male child diagnosed with intracranial malignant germ cell tumour received packed red cell transfusions at the University Malaya Medical Centre (UMMC), Malaysia in August 2012 for chemotherapyinduced anaemia. He received blood from three donors: a Myanmarese male and two Malaysian donors. A week later, upon returning to his home state, the patient started developing malaria-like symptoms. He sought consultation at the local hospital and was diagnosed with malaria following a blood test. He then returned to UMMC for further treatment. Blood samples from the patient and the three donors were sent to the Department of Parasitology, Faculty of Medicine, University of Malaya for further testing.

Giemsa-stained (5\%) blood smear from the patient was prepared and examined under light microscope. Examination of the slide was carried out by a skilled microscopist and visualization of the blood smear showed a $0.03 \%$ parasitaemia $P$. vivax infection. Polymerase chain reaction (PCR) was carried out on the blood samples of the patient and the three donors to confirm the species of the malaria parasite. DNA was extracted from $100 \mu \mathrm{l}$ of whole blood from the patient and the three donors using the DNeasy Blood \& Tissue Kit (QIAGEN, Valencia, CA, USA). Nested PCR was performed based on the amplification of the 
small subunit ribosomal (SSU r) RNA gene developed previously [6]. The nest 1 reaction mixture of $25 \mu \mathrm{l}$ contained $4 \mu \mathrm{l}$ of DNA template, $5 \mathrm{pmol}$ of nest 1 genus-specific primers (rPLU1: 5' -TCA AAG ATT AAG CCA TGC AAG TGA-3' and rPLU5: 5'-CCT GTT GTT GCC TTA AAC TCC-3'), 1× PCR buffer (35 mM Tris-HCl, pH 9.0, $3.5 \mathrm{mM} \mathrm{MgCl} 2,25 \mathrm{mM} \mathrm{KCl}, 0.01 \%$ gelatine), $0.25 \mathrm{M} \mathrm{dNTP}$, $1 \mathrm{u}$ Taq polymerase and $15.3 \mu \mathrm{l}$ of nuclease free water. The nest 1 amplification conditions were as follows: 1) initial denaturation at $94^{\circ} \mathrm{C}$ for $4 \mathrm{~min}$, 2) 35 cycles of denaturation at $94^{\circ} \mathrm{C}$ for $30 \mathrm{sec}$, annealing at $55^{\circ} \mathrm{C}$ for $1 \mathrm{~min}$ and extension at $72^{\circ} \mathrm{C}$ for $1 \mathrm{~min}, 3$ ) final extension at $72^{\circ} \mathrm{C}$ for $10 \mathrm{~min}$ and a hold temperature of $4^{\circ} \mathrm{C}$. Each of the nest 2 amplification mixture of $25 \mu \mathrm{l}$ contained $4 \mu \mathrm{l}$ of the nest 1 product and same amounts of buffer, dNTP, Taq polymerase and nuclease free water as in nest 1 . The primer sets used in nest 2 were as follows: (rPLU3: 5'-TTT TTA TAA GGA TAA CTA CGG AAA AGC TGT-3'and rPLU4: 5'-TAC CCG TCA TAG CCA TGT TAG GCC AAT ACC-3') for genus specific identification, FAL1: 5'-TTA AAC TGG TTT GGG AAA ACC AAA TAT ATT-3' and FAL2: 5' -ACA CAA TGA ACT CAA TCA TGA CTA CCC GTC-3' for Plasmodium falciparum, VIV1: 5'-CGC TTC TAG CTT AAT CCA CAT AAC TGA TAC-3' and V1V2: 5'-ACT TCC AAG CCG AAG CAA AGA AAG TCC TTA-3' for P. vivax, OVAL1: 5 '-ATC TCT TTT GCT ATC TTT TTT TAG TAT TGG AGA- 3' and OVAL2: 5'-GGA AAA GGA CAC ATT AAT TGT ATC CTA GTG-3' for Plasmodium ovale, MAL1: 5'-ATA ACA TAG TTG TAC GTT AAG AAT AAC CGC-3' and MAL2: 5' -AAA ATT CCC ATG CAT AAA AAA TTA TAC AAA- 3' for Plasmodium malariae, Pmk8: 5'-GTT AGC GAG AGC CAC AAA AAA GCG AAT-3' and Pmkr9: 5'-ACT CAA AGT AAC AAA ATC TTC CGT A-3' for Plasmodium knowlesi. The nest 2 cycling conditions were identical to that of nest 1 except that an annealing temperature of $58^{\circ} \mathrm{C}$ was used for the species-specific primers. The PCR products were purified with QIAquick Gel Extraction Kit (QIAGEN, Valencia, CA, USA) and cloned into pGEM-T Vector Systems (Promega, Wisconsin, USA) prior to DNA sequencing. Ethical approval for this study was obtained from the Medical Ethics Committee of University Malaya Medical Centre (Reference no: 817.18).

Based on the PCR results, it was confirmed that the Myanmarese male donor was infected with $P$. vivax and the other two donors were found to be negative for malaria. The 26-year-old donor is from Sagaing Region, Myanmar and first came to Malaysia in 2008 and worked until June 2011 in Semenyih, Selangor. He then returned to Myanmar for four months and resumed working in Semenyih from October 2011 till today. The medical history of the donor did not suggest prior malaria infection nor was there other significant medical or surgical history. There was no prior history of receiving blood transfusion either. He first donated blood on 1 July, 2012 at a mobile blood campaign organized by UMMC in Kuala Lumpur. The donor was examined via microscopy during the donation but no parasites were detected.

An amplification size of 120 bp was observed for both the patient and the Myanmarese donor DNA samples (Figure 1). Sequence alignment studies using Clustal W 2.1 revealed that the two sequences from both individuals were exactly the same (Figure 2).

\section{Discussion}

While malaria is endemic throughout most of the tropics, transmission of malaria is an unusual event in a nonendemic area. However, transmission is possible under certain circumstances such as (i) transmission by local competent mosquito vectors (ii) being infected by infective mosquitoes, that travelled aboard an airplane or within pieces of baggage to non-endemic areas (iii) nosocomial transmission, which involves a single incident of transmission to individual patients or hospital staff by blood transfusions, contingent needle-stick injuries or organ transplants $[7,8]$. In this report, transmission of malaria via blood transfusion between the patient and donor based on molecular investigations has been demonstrated.

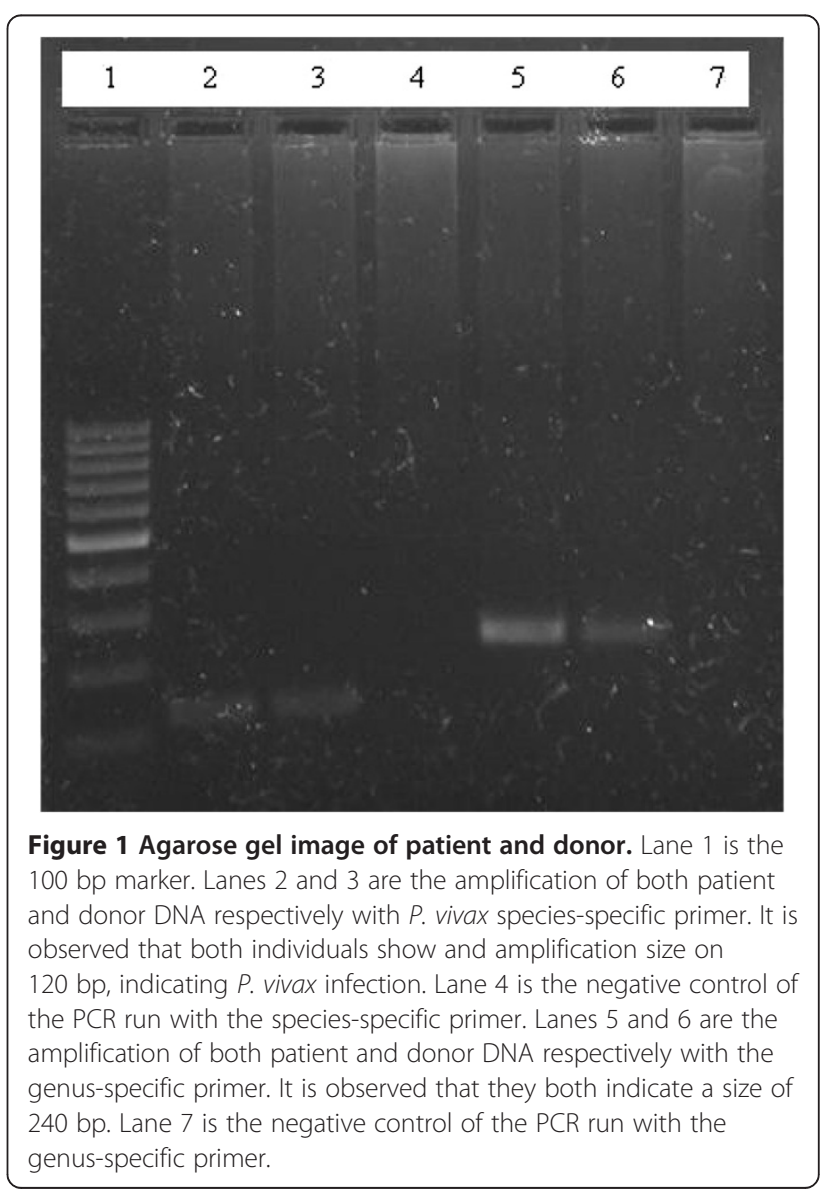


In order for parasites to be transmitted by blood transfusion, parasites must circulate in the blood stream of donors, show certain physical characteristics and be able to survive conservation [2,9]. Such is the case with symptomatic malaria donors. In asymptomatic malaria donors however, the lack of clinical manifestations and subpatent level of parasites makes diagnosing the infection a difficulty [10]. Malaria presents itself as a febrile haemolytic disease that poses a greater threat to pregnant, asplenic or immunosuppressed patients [11]. It is a known fact that all four human malaria parasites ( $P$. falciparum, $P$. vivax, $P$. ovale, and $P$. malariae) may be transfusion-transmitted [12]. After the first report in 1911, P. vivax was the predominant species until the 1950 s when $P$. malariae replaced it as the most common causative agent [5]. In the 1970s, P. vivax was again the most common, followed by P. malariae and P. falciparum. An increasing number of transfusion-transmitted $P$. falciparum cases were observed at the same time with a high mortality rate [13]. In the past decade or so, several transfusion-transmitted malaria cases have been reported in Brazil [14,15], France [16], Republic of Korea [17], Colombia [18], USA [19] and UK [20].

Any blood component containing erythrocytes can harbour viable parasites. Whole blood and red blood cell (RBC) represent the most common sources of TTM. However, cases involving leukocytes, platelets, fresh frozen plasma, and frozen RBCs have been previously reported $[5,14]$. In both malaria-endemic and non-endemic countries, TTM can be a problem due to several characteristics of malaria infection: (a) partially immune individuals with low level parasitaemia remain asymptomatic and can qualify as blood donors; (b) Plasmodium is able to survive in blood stored at $4^{\circ} \mathrm{C}$; and, (c) the sensitivity of the methods currently in use for detection of malaria is much lower than that required to detect level of parasitaemia capable of causing TTM [14,21]. In this case, it is possible that examination might have been performed by a non-expert who overlooked the donor as a potential threat due to sub-patent parasitaemia count. While blood safety remains an issue of great concern in transfusion medicine in all countries, it is of greater concern in developing countries where blood transfusion policies, trained personnel, appropriate infrastructure and financial resources are lacking or inadequate [1].

The donor, as previously mentioned, is from Sagaing Division, Myanmar. This location is situated in the north-west of Myanmar between Chin State on the west, Kachin State on the north-east, Shan State on the east and Magway Division and Mandalay Division on the south. Malaria is a major health issue in Myanmar, where resistant $P$. falciparum has already emerged [22]. Myanmar records an estimated 4.2 million cases annually and $69 \%$ of its population lives in malaria-endemic areas. Myanmar accounts for $75 \%$ of malaria cases and fatalities in the Mekong region and drug resistant malaria poses a greater threat [23]. In Sagaing Division, malaria cases are more prevalent in the months of June through November. These cases are predominantly due to $P$. falciparum but there are cases that are attributed to $P$. vivax as well [24]. In 2008, this division recorded an alarming 116,080 malaria cases, which placed it in second position from a list of 17 tested states/divisions [25]. It is an established fact that repeated exposure to malaria infection enables individuals to be protected against the disease as they would have progressively acquired antiparasite immunity [26]. Acquired semi-immunity could very well be the scenario with the donor as he comes from a region where transmission levels are high. Following an attack of malaria, a donor may remain infective for a long period of time, i.e., one to three years in P. falciparum, three to four years in $P$. vivax and for as long as 50 years in P. malariae [27].

Measures to monitor and assess transfusion transmission of infection, associating this to donor risk and evaluating possible threats to safety are pertinent [28]. There are two pivotal aspects to consider when taking into account malaria risk and transfusion: first, identification of malaria risk donors and second, managing the risk donors by either deferral or screening (including information of travel history and previous infection) [2,3]. A recent International Forum showed 
that in Europe and America, screening of donors by questionnaire is known to be the major deciding factor in prevention of transfusion-associated protozoan diseases [29]. It has been noted that most of the non-endemic countries follow the rule of donor deferral for 3 years after a donor has been infected with malaria [29]. While the development of donor-deferral guidelines that are appropriate to the country and to the donor population is of utmost importance to donor screening, one must bear in mind that complete prevention of TTM may not be possible [4]. In non-endemic countries, risk of transmission is minimized through donor deferral together with specific antimalarial antibody screening. In endemic countries however, more thorough donor questioning is required. This is coupled with knowledge of geographical distribution and seasonal variation to aid the identification of possibly infected donors [3]. A recent publication indicated that although malaria parasites are commonly found in the blood of donors in malariaendemic areas, TTM does not occur frequently [30].

Before blood donation, the donor is required to fill out a consent and assessment form. Based on standard procedures, prior transfusion, a donor's blood is subject to two tests. The first being the $\mathrm{ABO}$ blood group test and the second is a virology test, whereby the donor's blood is screened for HIV, hepatitis B, hepatitis C and syphilis. In the rare event there are donors from malaria endemic countries, microscopic examination is performed to identify donors who may be potentially infected.

\section{Conclusion}

Although no set of guidelines is flawless, appropriate deferral strategies coupled with appropriate laboratory screening will reduce the risk of TTM to a minimum. Donor selection is particularly difficult in healthy asymptomatic adults as they do not have fever and questionnaires do not identify such donors. However, with more rigorous questioning, there is a possibility of overcoming this problem. The in vitro processing of donor blood with antimalarials to kill parasites prior transfusion is also another measure to prevent TTM. In this study, the authors report a $P$. vivax transfusion-transmitted case which to the best of the authors' knowledge is the first reported incident in Malaysia.

\section{Consent}

Consent was granted by the patient for the publication of this case report.

\section{Competing interests}

The authors declare that they have no competing interests.

\section{Authors' contributions}

CNA and LYL drafted and wrote the article, SJS performed the molecular diagnosis of the blood samples, FMY carried out the sequence analysis. RM performed the microscopy analysis, ZWL and IJ were the clinicians who dealt with the transfusion case. HA was the paediatrician attending to the patient. All authors read and approved the final manuscript.

\section{Acknowledgements}

This study was supported by University of Malaya, High Impact Research Fund (UM.C/625/1/HIR/MOHE/CHAN/14/3) and Postgraduate Research Grant of University of Malaya (PV030/2011A and PV044/2012A). We would like to acknowledge the staff at UMMC and the local state hospital who attended to this case.

\section{Author details}

'Department of Parasitology, Faculty of Medicine, University Malaya, 50603, Kuala Lumpur, Malaysia. ${ }^{2}$ Department of Paediatrics, Faculty of Medicine, University Malaya, 50603, Kuala Lumpur, Malaysia. ${ }^{3}$ University Malaya Medical Centre, Lembah Pantai, 59100, Kuala Lumpur, Malaysia.

Received: 1 April 2013 Accepted: 20 August 2013

Published: 4 September 2013

\section{References}

1. Ekwunife CA, Ozumba NA, Eneanya Cl, Nwaorgu OC: Malaria infection among blood donors in Onitsha Urban, South Nigeria. Sierra Leone J Biomed R 2011, 3:21-26.

2. Singh G, Sehgal R: Transfusion-transmitted parasitic infections. Asian J Transfus Sci 2010, 4:73-77.

3. Kitchen AD, Chiodini PL: Malaria and blood transfusion. Vox Sang 2006, 70:77-84.

4. Slinger R, Giulivi A, Bodie-Collins M, Hindieh F, St John R, Sher G, Goldman M, Ricketts M, Kain KC: Transfusion-transmitted malaria in Canada. CMAJ 2001, 164:377-379.

5. Seed CR, Kitchen A, Davis TME: The current status and potential role of laboratory testing to prevent transfusion-transmitted malaria. Transfus Med Rev 2005, 19:229-240.

6. Singh B, Lee KS, Matusop A, Radhakrishnan A, Shamsul SS, Cox-Singh J, Thomas A, Conway DJ: A large focus of naturally acquired Plasmodium knowlesi infections in human beings. Lancet 2004, 363:1017-1024.

7. Zoller T, Naucke TJ, May J, Hoffmeister B, Flick H, Williams CJ, Frank C, Bergmann F, Suttorp N, Mockenhaupt FP: Malaria transmission in nonendemic areas: case report, review of the literature and implications for public health management. Malar J 2009, 8:71.

8. Kirchgatter K, Wunderlich G, Branquinho MS, Salles TM, Lian YC, CarneiroJunior RA, Di Santi SM: Molecular typing of Plasmodium falciparum from Piemsa-stained blood smears confirms nosocomial malaria transmission. Acta Trop 2002, 84:199-203.

9. Garraud O: Mechanisms of transfusion-linked parasite infection [in French]. Transfus Clin Biol 2006, 13:290-297.

10. Laishram DD, Sutton PL, Nanda N, Sharma VL, Sobti RC, Carlton JM, Joshi H: The complexities of malaria disease manifestations with a focus on asymptomatic malaria. Malar J 2012, 11:29.

11. Marshall CS, Unger KM, Deckard-Janatpour K: Risks of blood transfusion: challenges for the 21st century. Semin Anesth 1998, 17:195-207.

12. Uneke CJ, Ogbu O, Nwojiji V: Potential risk of induced malaria by blood transfusion in south-eastern Nigeria. McGill J Med 2006, 9:8-13.

13. Bruce-Chwatt LT: Transfusion malaria revisited. Trop Dis Bull 1982, 79:827-840.

14. Scuracchio P, Vieira SD, Dourado DA, Bueno LM, Colella R, Ramos-Sanchez EM, Lima GFMC, Inoue J, Sanchez MCA, Di Santi SM: Transfusiontransmitted malaria: case report of asymptomatic donor harbouring Plasmodium malariae. Rev Inst Med Trop Sao Paulo 2011, 53:55-59.

15. Kirchgatter K, Nogueira SL, Padilha A, Curado I, Boulos M, Di Santi SM: Lethal malaria caused by Plasmodium malariae in an asplenic patient in Brazil. BMJ 2005, 331(7516):576b.

16. Garraud O, Assal A, Pelletier B, Danic B, Kerleguer A, David B, Joussemet M, de Micco P: Overview of revised measures to prevent malaria transmission by blood transfusion in France. Vox Sang 2008, 95:226-231.

17. Lee YH, Lee HK, Choi KH, Hah JO, Lim SY: Transfusion-induced malaria in a child after open heart surgery in Korea. J Korean Med Sci 2001, 16:789-791.

18. Echeverri D, Barreto DK, Osorio L, Cortes A, Martinez E: A case report of transfusion-transmitted Plasmodium vivax malaria from an asymptomatic donor to a premature newborn [in Portuguese]. Biomedica 2012, 32:8-12.

19. Reesink HW, Panzer S, Wendel S, Levi JE, Ullum H, Ekblom-Kullberg S, Seifried E, Schmidt M, Shinar E, Prati D, Berzuini A, Ghosh S, Flesland O, Jeansson S, Zhiburt E, Piron M, Sauleda S, Ekermo B, Eglin R, Kitchen A, Dodd RY, Leiby DA, Katz LM, Kleinman S: The use of malaria antibody tests 
in the prevention of transfusion-transmitted malaria. Vox Sang 2010, 98:468-478.

20. Kitchen A, Mijovic A, Hewitt P: Transfusional transmitted malaria: current donor selection guidelines are not sufficient. Vox Sang 2005, 88:200-201.

21. Dubey A, Elhence $P$, Ghoshal U, Verma A: Seroprevalence of malaria in blood donors and multi-transfused patients in Northern India: relevance to prevention of transfusion-transmissible malaria. Asian J Transfus Sci 2012, 6:174-178.

22. Ejov MN, Tun T, Aung S, Sein K: Response of falciparum malaria to different antimalarials in Myanmar. Bull World Health Organ 1999, 77:244-249.

23. Regional cooperation is needed to fight malaria in Myanmar. http://www. ausaid.gov.au/HotTopics/Pages/Display.aspx?QID=857.

24. Malaria site: malaria in Asia. http://www.malariasite.com/malaria/asia.htm.

25. 2009-Asian collaborative training network for malaria. http://www.actmalaria. net/IRW/IRW_Myanmar.pdf.

26. Soe $S$, Druilhe $P$ : The implications of naturally acquired immunity to malaria in Southeast Asia. Trends Parasitol 2002, 18:8-10.

27. Modi C, Padalia U, Patil RC: A case study of possible relationship between post transfusion malaria and thalassaemia. Asian J Exp Sci 2008, 22:109-112

28. O'Brien SF, Zou S, Laperche S, Brant LJ, Seed CR, Kleinman SH: Surveillance of transfusion-transmissible infections: comparison of systems in five developed countries. Transfus Med Rev 2012, 26:38-57.

29. Chauhan V, Negi RC, Verma B, Thakur S: Transfusion-transmitted malaria in a non-endemic area. JAPI 2009, 57:653-654

30. Owusu-Ofori AK, Betson M, Parry CM, Stothard JR, Bates I: Transfusiontransmitted malaria in Ghana. Clin Infect Dis 2013, 56:1735-1741.

doi:10.1186/1475-2875-12-308

Cite this article as: Anthony et al:: Malaysian child infected with Plasmodium vivax via blood transfusion: a case report. Malaria Journal 2013 12:308

\section{Submit your next manuscript to BioMed Central and take full advantage of:}

- Convenient online submission

- Thorough peer review

- No space constraints or color figure charges

- Immediate publication on acceptance

- Inclusion in PubMed, CAS, Scopus and Google Scholar

- Research which is freely available for redistribution 